\title{
Query Expansion menggunakan Word Embedding dan Pseudo Relevance Feedback
}

\author{
Evan Tanuwijaya a, Safri Adam b, Mohammad Fatoni Anggris c, Agus Zainal Arifin ${ }^{\text {d }}$ \\ $a, b, c, d$ Teknik Informatika, Institut Teknologi Sepuluh Nopember, Surabaya, Indonesia \\ email:aevantanuwijaya.18051@mhs.its.ac.id, bsafriadam.18051@mhs.its.ac.id, cmohammadanggris.18051@mhs.its.ac.id, \\ dagusza@cs.its.ac.id
}

\begin{tabular}{l}
\hline I N F O A R T I K E L \\
\hline Sejarah artikel: \\
Menerima 19 Desember 2018 \\
Revisi \\
17 April 2019 \\
Diterima 11 Mei 2019 \\
Online 29 Mei 2018 \\
\hline
\end{tabular}

Kata kunci:

Pseudo Relevant Feedback

Query Expansion

Word Embedding

Keywords:

Pseudo Relevant Feedback

Query Expansion

Word Embedding

\section{Style APA dalam menyitasi} artikel ini.

Tanuwijaya, E., Adam, S., Anggris, M. F., \& Arifin, A. Z. (2019). QE menggunakan Word Embedding dan Pseudo Relevance Feedback. Register: Jurnal Ilmiah Teknologi Sistem Informasi, 5(1), 47-54.

\begin{abstract}
ABSTRAK
Kata kunci merupakan hal terpenting dalam mencari sebuah informasi. Penggunaan kata kunci yang tepat menghasilkan informasi yang relevan. Saat penggunaannya sebagai query, pengguna menggunakan bahasa yang alami, sehingga terdapat kata di luar dokumen jawaban yang telah disiapkan oleh sistem. Sistem tidak dapat memproses bahasa alami secara langsung yang dimasukkan oleh pengguna, sehingga diperlukan proses untuk mengolah katakata tersebut dengan mengekspansi setiap kata yang dimasukkan pengguna yang dikenal dengan Query Expansion (QE). Metode QE pada penelitian ini menggunakan Word Embedding karena hasil dari Word Embedding dapat memberikan kata-kata yang sering muncul bersama dengan kata-kata dalam query. Hasil dari word embedding dipakai sebagai masukan pada pseudo relevance feedback untuk diperkaya berdasarkan dokumen jawaban yang telah ada. Metode QE diterapkan dan diuji coba pada aplikasi chatbot. Hasil dari uji coba metode QE yang diterapkan pada chatbot didapatkan nilai recall, precision, dan F-measure masing-masing $100 \% ; 70 \%$ dan $82,35 \%$. Hasil tersebut meningkat $1,49 \%$ daripada chatbot tanpa menggunakan QE yang pernah dilakukan sebelumnya yang hanya meraih akurasi sebesar $68,51 \%$. Berdasarkan hasil pengukuran tersebut, QE menggunakan word embedding dan pseudo relevance feedback pada chatbot dapat mengatasi query masukan dari pengguna yang ambigu dan alami, sehingga dapat memberikan jawaban yang relevan kepada pengguna.
\end{abstract}

\section{ABSTRACT}

Keywords are the most important words and phrases used to obtain relevant information on content. Although users make use of natural languages, keywords are processed as queries by the system due to its inability to process. The language directly entered by the user is known as query expansion (QE). The proposed $Q E$ in this research uses word embedding owing to its ability to provide words that often appear along with those in the query. The results are used as inputs to the pseudo relevance feedback to be enriched based on the existing documents. This method is also applied to the chatbot application and precision, and F-measure values of the results obtained were $100 \%, 70 \%, 82.35 \%$ respectively. The results are $1.49 \%$ better than chatbot without using $Q E$ with $68.51 \%$ accuracy. Based on the results of these measurements, QE using word embedding and pseudo which gave relevance feedback in chatbots can resolve ambiguous and natural user's input queries thereby enabling the system retrieve relevant answers.

(c) 2019 Register: Jurnal Ilmiah Teknologi Sistem Informasi. Semua hak cipta dilindungi undang-undang.

\section{Pendahuluan}

Informasi sangat dibutuhkan oleh semua orang. Dalam mencari suatu informasi, banyak orang menggunakan bahasa yang beragam. Keragaman bahasa tersebut dapat mempengaruhi pencarian informasi seperti penggunaan, pemaknaan, bahkan gabungan kata. Pada sebuah sistem, dibutuhkan 
sebuah proses agar dapat memahami keberagaman bahasa yang digunakan oleh orang-orang tersebut, karena bahasa yang digunakan untuk mencari informasi merupakan kata kunci yang penting dalam mencari sebuah informasi. Kata kunci atau query yang tepat akan menghasilkan informasi yang sesuai. Namun, bahasa yang digunakan untuk memasukkan query tersebut beragam dan bahkan ambigu, sehingga informasi yang didapatkan bisa sesuai dengan yang diinginkan dan juga tidak (Dalpiaz, Ferrari, Franch, \& Palomares, 2018). Dalam hal ini, perlu adanya proses untuk mengenali query yang dimasukkan agar sistem dapat menarik informasi yang sesuai.

Untuk meningkatkan kinerja penarikan informasi dilakukan beberapa cara, salah satunya dengan melakukan Query Expansion (QE) (Nie, Jiang, Ren, Sun, \& Li, 2016) yang berguna untuk memperkaya sebuah query. Pada $\mathrm{QE}$, query dimasukkan oleh pengguna dan diproses oleh sistem kemudian ditambahkan dengan term baru yang mirip dengan query yang dimasukkan, sehingga menghasilkan query baru yang lebih sesuai (Lee \& Lee, 2014). Digunakannya QE mempermudah sistem menarik informasi yang lebih sesuai dengan query yang dicari oleh pengguna dan diharapkan mampu menyelesaikan masalah query yang tidak akurat.

Metode QE yang pernah diterapkan salah satunya menggunakan relevance feedback (Ooi, Ma, Qin, \& Liew, 2015). Namun, beberapa masalah seperti kesalahan ejaan, lintas bahasa, dan ketidakcocokan antara kosakata pengguna dengan kosakata pada dokumen tidak bisa diselesaikan hanya dengan relevance feedback. Oleh karena itu, diperlukan metode yang dapat mengatasi masalah tersebut dengan menggunakan word embedding yang dapat menangkap informasi semantik dan sintaksis kata-kata dari korpus besar yang tidak berlabel. Dengan menggunakan metode ini, sistem dapat memproses bahasa alami atau Natural Language Processing (NLP) (Dalpiaz, Ferrari, Franch, \& Palomares, 2018) dengan mengambil informasi dari bahasa tersebut dan mengetahui hubungan makna antara suatu kata (Şenel, Utlu, Yücesoy, Koç, \& Çukur, 2018). Informasi dari kata-kata tersebut direpresentasikan ke dalam masing-masing vektor. Salah satu tipe relevance feedback yang sering digunakan adalah explicit feedback yaitu memanfaatkan bukti eksplisit yang menunjukan relevansi dari sebuah dokumen. Pseudo relevance feedback adalah salah satu bagian dari jenis explicit feedback. Pseudo relevance feedback merupakan metode expansion query yang digunakan dengan mencocokkan term pada query dengan term yang ada pada dokumen yang ingin ditunjukan (Yan \& Gao, 2017). Nilai dari hasil pencocokan term terhadap masingmasing dokumen akan dibandingkan dengan nilai dari dokumen yang lain. Kemudian, dokumen yang memiliki nilai tertinggi tersebut akan dipakai sebagai dokumen yang sesuai dengan query yang diinputkan oleh pengguna. Akan tetapi, term pada query yang dimasukkan oleh pengguna harus semirip mungkin dengan term pada dokumen agar metode ini dapat efektif $(\mathrm{Xu}$, Lin, Lin, Yang, \& Xu, 2018).

Word embedding sedang menunjukkan kemampuannya dalam bidang pemrosesan bahasa alami dan Information Retrieval (IR) (Liu, Huang, Lut, Gao, \& Zhang, 2017). Oleh sebab itu, dalam penelitian ini, digunakan metode word embedding sebagai metode utama. Namun, word embedding memiliki kelemahan yaitu menghasilkan banyak term yang memiliki tema sangat luas, bahkan di luar dari query awal. Maka, perlu digabungkan dengan pseudo relevance feedback sehingga dapat menyederhanakan query dari hasil word embedding disesuaikan dengan dokumen pertanyaan yang telah disiapkan oleh sistem. Penelitian ini mengusulkan metode QE dengan mengombinasikan word embedding dengan pseudo relevance feedback. Penelitian ini dilakukan untuk mengatasi pertanyaan atau query dari pengguna yang tidak tersedia pada dokumen yang telah disiapkan.

\section{State of the Art}

Dalam Sistem Temu Kembali Informasi (STKI), telah banyak penelitian yang dilakukan terkait query expansion (QE), word embedding, dan pseudo-relevance feedback. Pada bagian ini, akan dibahas beberapa dasar dari penelitian yang telah dilakukan sebelumnya.

\subsection{Query Expansion (QE)}

Dalam pengambilan data pada sebuah basis data ataupun dokumen, perlu adanya masukan berupa query (Reshma \& Remya, 2017). Query yang dimasukkan oleh pengguna haruslah tepat agar dapat menarik informasi yang tepat. Namun, banyak pengguna memasukkan query yang tidak dapat dimengerti oleh sistem. Hal ini menyebabkan informasi yang terambil menjadi kurang sesuai bahkan 
tidak terambil (Reshma \& Remya, 2017). Query Expansion (QE) merupakan sebuah metode untuk mengembangkan query yang dimasukkan oleh pengguna agar query tersebut dapat menarik informasi yang sesuai (Nie, Jiang, Ren, Sun, \& Li, 2016).

Terdapat dua pendekatan QE, yaitu secara global dan lokal (Reshma \& Remya, 2017). Global Query Expansion yaitu query yang dimasukkan dicari kemiripan berupa sinonim dan lain-lain pada kata dari sebuah tesaurus. Kemudian, hasil pencocokan tersebut akan ditambahkan ke dalam query, sehingga query menjadi lebih kaya. Local Query Expansion yaitu query yang dimasukkan dibandingkan dengan dokumen yang telah disediakan di awal, bukan dari tesaurus.

Banyak penelitian yang dilakukan untuk mengembangkan metode QE agar lebih akurat. Salah satunya adalah dengan memanfaatkan sinonim dari sebuah kata yang diusulkan oleh Imrandan dan Nohama (Putra, Effendi, \& Arifin, 2018). Selanjutnya, dengan pendekatan morfologi, derivasi leksikal, dan kesamaan semantik semacam sinonim diusulkan oleh Pasca (Ludviani, Hayati, Arifin, \& Purwitasari, 2015) yang memiliki batasan yang bergantung pada sumber informasi atau data yang digunakan.

\subsection{Word Embedding}

Word embedding mengenali distribusi makna kata yang serupa yang kemudian dikenali pada sebuah model vector (Şenel, Utlu, Yücesoy, Koç, \& Çukur, 2018). Dengan menangkap karakteristik kata-kata, baik itu kata aslinya maupun kata yang mirip, perlu dihitung kemiripan kata yang satu dengan kata yang lain. Dengan menggunakan rumus cosine similarity, sistem dapat mengenali kemiripan antarkata pada sebuah vektor. Word embedding biasanya dipakai dalam tahap pertama untuk melakukan proses deep learning sebuah informasi (Young, Hazarika, Poria, \& Cambria, 2018).

Telah banyak penelitian terdahulu mengenai word embedding. Salah satunya penelitian dari Bengio (Young, Hazarika, Poria, \& Cambria, 2018) yang membuat sebuah model Neural Network yang belajar model dari sebuah bahasa untuk membangun sebuah word embedding mirip dengan konsep Neural Network. Hanya saja, pada model ini, digunakan log-bilinear energy yang menggantikan rumus tanh pada Neural Network.

\subsection{Pseudo-Relevance Feedback}

Pseudo relevance feedback merupakan metode untuk analisis query lokal otomatis dan tidak melibatkan pengguna dalam perolehan keputusannya (Wang, Fang, \& Zhai, 2008). Cara kerja pseudo relevance feedback adalah dengan mengambil dokumen sebanyak $K$ teratas secara sederhana dan mengasumsikan dokumen tersebut relevan. Jika pengambilan dokumen $K$ teratas dengan alasan yang cukup, sistem akan mengambil query atau terms yang baik pula. Namun, bila pengambilan dokumen tidak bagus, terjadi pengambilan query atau terms yang buruk ( $\mathrm{Xu}$, Lin, Lin, Yang, \& Xu, 2018) (Mothe, et al., 2015).

Dalam proses QE yang menggunakan pseudo relevance feedback, digunakan algoritma Rocchio sebagai pembentukan vector space model untuk menentukan relevance feedback query. Dalam proses pembentukan initial query menjadi query baru, algoritma Rocchio akan menentukan dokumen yang relevan dan dokumen yang tidak relevan. Initial query yang dimasukkan oleh pengguna akan terletak pada centroid seluruh dokumen, baik dokumen yang relevan maupun tidak (Buckley, Salton, \& Allan, 1994) (Dierk, 1972). Berdasarkan nilai centroid tersebut, didapatkan query baru yang diambil berdasarkan dokumen yang paling relevan (Dierk, 1972).

\section{Metode Penelitian}

Penelitian ini mengusulkan QE menggunakan word embedding dan pseudo relevance feedback. Pengembangan metode ini dilakukan dengan bahasa pemrograman Python. Pengguna yang menginginkan informasi seputar kehamilan akan memasukkan pertanyaan ke dalam sistem. Kemudian, sistem akan melakukan preprocessing terhadap query tersebut. Setelah dilakukan preprocessing, dilakukan QE yang diusulkan dalam penelitian ini, yaitu word embedding dan pseudo relevance feedback. Hasil dari QE kemudian akan dipakai untuk menarik jawaban yang sesuai. Tahapan metode penelitian yang diusulkan dapat dilihat pada Gambar 1.

Dari proses QE yang telah dijelaskan sebelumnya, selanjutnya diimplementasikan ke dalam bahasa pemograman Python dan library yang mendukung. Program dipasang pada aplikasi chat Line 
menggunakan Line SDK. Pada aplikasi Line tersebut, dibuat sebuah akun konsultasi ibu hamil yang dapat digunakan untuk konsultasi dengan cara memberi pertanyaan kepada chatbot, kemudian akan dijawab oleh program bot yang telah dikembangkan.

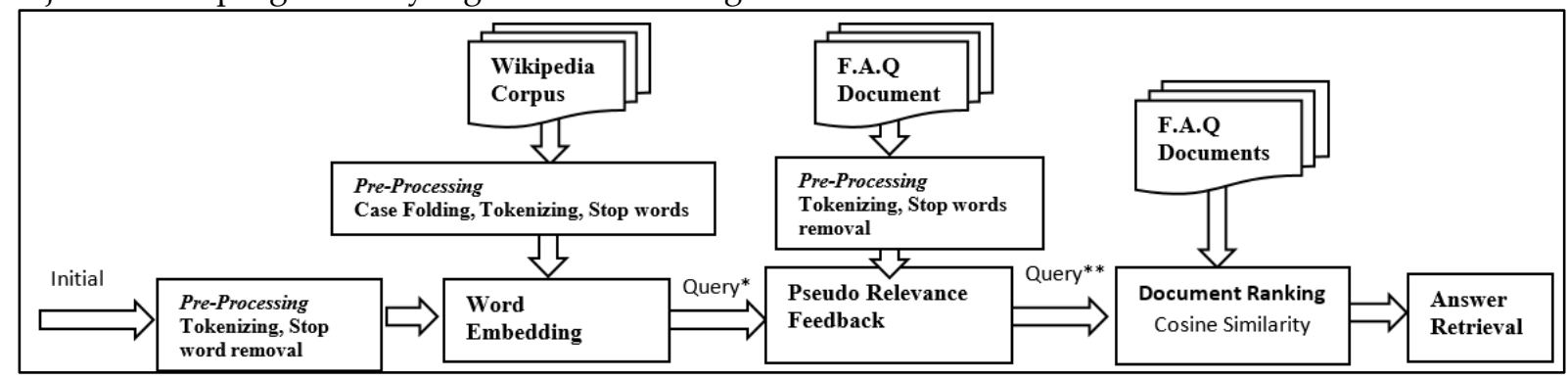

Gambar 1. Tahapan metode penelitian

\subsection{Data dan Dokumen Jawaban}

Dalam penelitian ini, QE diterapkan pada aplikasi chatbot. Query yang dimasukan ke dalam sistem berupa pertanyaan dari pengguna, sedangkan dokumen yang akan diambil adalah jawaban yang telah disiapkan. Implementasi pada aplikasi chatbot difokuskan pada pertanyaan dan jawaban seputar konsumsi makanan dan minuman pada ibu hamil. Hal ini bertujuan agar data yang diproses tidak terlalu besar. Maka, dikumpulkan data berupa dokumen yang terkait dengan konsumsi makanan dan minuman ibu hamil. Dokumen tersebut berisi jawaban-jawaban dari pertanyaan yang biasanya ditanyakan oleh ibu hamil. Dokumen tersebut didapatkan dari berbagai sumber, seperti blog pribadi dokter spesialis kandungan (Agung, 2011), Kumpulan Pertanyaan Seputar Ibu Hamil (Indarini, 2018), dan website Fakultas Kedokteran (Fitriana, 2016). Data tersebut dikumpulkan dan diringkas menjadi 16 pasang pertanyaan dan jawaban yang kemudian menjadi 16 dokumen. 16 dokumen tersebut ditetapkan label kelas untuk setiap 1 dokumen. Label dalam dokumen pertanyaan jawaban tersebut berupa term unik dari setiap dokumen. Term tersebut tidak terdapat dalam dokumen lainnya. Penentuan label nantinya digunakan untuk mencari threshold sebagai batas minimal kemiripan antara dokumen dan query yang akan dikeluarkan sebagai jawaban dari chatbot.

\subsection{Preprocessing}

Teks masukan dari pengguna berupa pertanyaan akan dilakukan preprocessing terlebih dahulu. Dokumen yang perlu dilakukan pada preprocessing yaitu query, corpus Wikipedia Bahasa Indonesia, dan dokumen Frequently Asked Questions (FAQ). Tahap pertama yang dilakukan yaitu case folding, bertujuan mengubah semua huruf dalam dokumen menjadi huruf kecil dan karakter selain huruf akan dihilangkan. Tahap kedua adalah tokenization, yaitu pemotongan kalimat menjadi kata-kata yang berdiri sendiri. Pada tokenization dilakukan pemisahan tersebut berdasarkan spasi sebagai delimiter. Tahapan selanjutnya dilakukan stopword removal, yaitu menghilangkan kata-kata tidak penting seperti "di", "yang", "ke" dan lain-lain. Dalam stopword removal juga ditambahkan beberapa term yang harus dieliminasi. Penambahan ini dilakukan secara manual dengan menambahkan term tersebut pada dokumen koleksi term yang harus dieliminasi.

\subsection{Pseudo-Relevance Feedback}

Dalam penelitian ini digunakan word embedding sebagai expander query secara global. Secara khusus, peneliti menggunakan Word2Vec Continuous-Bag-Of-Word (C-BOW) yang mewakili ruang vektor tiap kata atau term berdasarkan co-occurrence di dalam jendela teks. Kemiripan antara vektor istilah ditunjukkan sesuai dengan persamaan semantik (Kuzi, Shtok, \& Kurland, 2016). Pada penelitian Kuzi, dkk. ini digunakan corpus Wikipedia Bahasa Indonesia sebagai dokumen train. Training akan dilakukan secara offline dan menghasilkan model yang isinya ruang vektor dari seluruh kata-kata yang ada pada corpus. Setelah dilakukan preprocessing, setelah dilakukan langsung dilakukan pengambilan kata-kata yang terdekat dari masing masing kata pada query dari user. Setiap kata akan diambil 5 yang terdekat dan disimpan sebagai 1 dokumen query baru.

\subsection{Pseudo Relevance Feedback}

Query Expansion menggunakan Word Embedding dan Pseudo Relevance Feedback $\quad$ http://doi.org/10.26594/register.v5i1.1385 (c) 2019 Register: Jurnal IImiah Teknologi Sistem Informasi. Semua hak cipta dilindungi undang-undang. 
Setelah melakukan QE dari word embedding, dihasilkan Query*, yaitu query yang sudah diekspansi dari query awal. Pada tahap pencarian bobot TFIDF Query* dihitung dengan seluruh dokumen jawaban. Hasil dari pembobotan TFIDF digunakan untuk mencari kedekatan antara Query* dengan seluruh dokumen. Pada tahap document ranking, dilakukan penghitungan cosine similarity dan diurutkan berdasarkan nilai terkecil. Selanjutnya, pada tahap Top K Document dipilih dokumen yang memiliki nilai cosine similarity terkecil. Pada tahap terakhir dilakukan proses seleksi query dan penambahan query berdasarkan $K$ dokumen menggunakan Rocchio algorithm. Pada Rocchio algorithm, proses pencarian akan menghasilkan dokumen yang relevan dan yang tidak. Query* yang dimasukkan oleh pengguna berada pada centroid dari seluruh dokumen, baik dokumen yang relevan maupun tidak. Proses penambahan Query* menjadi $\boldsymbol{q}_{\boldsymbol{m}}$ berdasarkan centroid dokumen yang paling relevan. $\boldsymbol{q}_{\boldsymbol{m}}$ dihasilkan dengan Persamaan 1,

$\overrightarrow{\boldsymbol{q}}_{m}=\alpha \overrightarrow{\boldsymbol{q}}_{0}+\boldsymbol{\beta} \frac{1}{\left|D_{r}\right|} \sum_{\overrightarrow{\boldsymbol{d}}_{j} \in D_{r}} \overrightarrow{\boldsymbol{d}}_{j}-\gamma \frac{1}{\left|D_{n r}\right|} \sum_{\vec{d}_{j} \in D_{n r}} \overrightarrow{\boldsymbol{d}}_{j}$

dengan $\boldsymbol{q}_{\boldsymbol{m}}$ adalah vektor $q u e r y$ baru yang kemudian dinotasikan sebagai $Q$ uery ${ }^{* *}$, sedangkan $\boldsymbol{q}_{\mathbf{0}}$ adalah vektor query awal. $\boldsymbol{d}_{\boldsymbol{j}}$ merupakan dokumen vector. $\boldsymbol{d}_{\boldsymbol{r}}$ adalah vektor dokumen relevan. $\boldsymbol{d}_{\boldsymbol{n} \boldsymbol{r}}$ adalah vektor dokumen nonrelevan. $\alpha$ adalah bobot query asli. $\beta$ adalah bobot dokumen relevan dan $\gamma$ adalah bobot dokumen nonrelevan.

\subsection{Pengambilan Jawaban}

Query yang telah diekspansi akan dipakai untuk mencari jawaban yang sesuai. Query yang berupa token term tersebut akan dicari kemiripan antar term dari masing-masing dokumen dengan menggunakan rumus cosine similarity. Nilai kemiripan tersebut kemudian dibandingkan dengan nilai masing-masing dokumen. Pada pengambilan jawaban ditetapkan treshoold yang berfungsi membatasi kemiripan jawaban yang akan diambil. Jika dokumen yang memiliki nilai cosine terbesar tetapi di bawah threshold, dokuken jawaban tidak akan ditarik. Namun, jika dokumen jawaban tersebut memiliki nilai cosine berada di atas threshold, dokumen tersebut akan diambil, kemudian akan ditampilkan kepada pengguna sebagai jawaban dari pertanyaan yang telah dimasukkan oleh pengguna.

\subsection{Precision, Recall, dan Harmonic Mean}

Pada penelitian ini, digunakan recall dan precision untuk mengukur seberapa baik performa QE dalam memperkaya query dengan kriteria confusion matrix. Kriteria True Positive (TP) untuk yang jawaban ada dan relevan dengan pertanyaan, kriteria False Positive (FP) untuk yang jawaban ada tetapi tidak relevan dengan pertanyaan, kriteria False Negative (FN) untuk yang tidak ada jawaban relevan yang diambil, kriteria False Negative (FN) untuk yang tidak ada jawaban yang tidak relevan yang diambil. Namun, precision dan recall adalah unsur yang saling berlawanan atau trade-off, maka diperlukan evaluasi yang dapat menoleransi trade-off tersebut dengan perhitungan F-measure yang merupakan weighted harmonic mean dari precesion dan recall. Titik nilai precision dan recall mencapai keseimbangan jika perhitungan $F$ measure mencapai 70\% (Domarco \& Iswari, 2017). Nilai recall, precision dan F-measure (F1) dapat dilihat pada Persamaan 2, Persamaan 3, dan Persamaan 4.

$$
\begin{aligned}
& \text { Recall }=\frac{T P}{T P+F N} \\
& \text { Precision }=\frac{T P}{T P+T N} \\
& F-\text { Measure }=\frac{2 \times \text { Precision } \times \text { Recall }}{\text { Precision }+ \text { Recall }}
\end{aligned}
$$

\section{Hasil dan Pembahasan}

Metode QE yang diusulkan telah diimplementasikan ke dalam aplikasi chatbot yang kemudian dilakukan uji coba. Tabel 1 adalah contoh hasil proses dari setiap tahap pada sistem. Pertama, pengguna memasukan pertanyaan sebagai query. Selanjutnya, sistem akan melakukan preprocessing kata berupa stopword, menghilangkan simbol dan mengubah pertanyaan menjadi token kata. Berikutnya, token tersebut dimasukkan ke proses QE. Pada tahap pertama, yaitu word embedding, masing-masing dari token dicari kemiripan katanya dan diambil 5 kata paling mirip kemudian ditambahkan sebagai query awal. 
Tabel 1. Proses menghasilkan QE

\begin{tabular}{|c|c|c|c|c|}
\hline Query & Pre-processing & Word Embedding & $\begin{array}{c}\text { Pseudo feedback } \\
\text { relevance }\end{array}$ & $\begin{array}{c}\text { Expanded } \\
\text { query }\end{array}$ \\
\hline
\end{tabular}

ayah ibunya mertua adik orangtua menyusui

bolehkah ibu [ 'ibu', 'hamil', hamil makan 'makan', 'tiram'] kehamilan bayinya haid persalinan
makannya sarapan minum memasak tidur

udang bandeng ketam cakalang kerang ibu

hamil makan tiram kerang sarapan ibu hamil makan kerang tiram sarapan ibu

hamil makan

Tahap pseudo relevance feedback yaitu mencari kemiripan kata pada query hasil word embedding dengan term pada dokumen pertanyaan dan jawaban. Hasil dari pseudo relevance feedback dipakai untuk mencari kemiripan dokumen. Threshold yang digunakan untuk batas bawah kemiripan antara query dan dokumen adalah nilai bobot cosine similarity. Threshold dihasilkan dari hasil observasi terhadap terhadap nilai cosine similarity. Dengan menggunakan label kelas dokumen sebagai query, didapat bobot cosine, lalu hasilnya disortir. Bobot cosine yang terkecil akan menjadi threshold. Jika pertanyaan yang diajukan oleh pengguna di bawah threshold, akan dibalas dengan pertanyan balik: "maaf bunda sebenarnya tanya apa? Silakan tanya dengan spesifik". Hasil uji coba threshold dari setiap metode dapat dilihat pada Tabel 2 pada kolom threshold cosine. Hasil observasi menunjukkan threshold yang berbeda-beda disebabkan setiap dokumen pertanyaan dan jawaban memiliki keunikan masing-masing, sehingga tidak bisa disamakan ambang batasnya. Jika semua threshold disamakan, sistem akan memberikan dokumen yang tidak relevan dengan query.

Untuk melakukan uji coba, disiapkan 10 pertanyaan yang terdiri atas 4 pertanyaan dari responden yang sedang hamil, 4 pertanyaan yang menggunakan bahasa sehari-hari, dan 2 pertanyaan yang tidak terdapat dalam dokumen jawaban chatbot. Sepuluh pertanyaan akan ditanyakan kepada chatbot. Hasil pengujian sistem chatbot dengan QE menggunakan word embedding dan pseudo relevance feedback dapat dilihat pada Tabel 2. Ditampilkan pula hasil pengujian sistem chatbot tanpa menggunakan $\mathrm{QE}, \mathrm{QE}$ dengan word embedding, dan QE dengan pseudo relevance feedback.

Tabel 2. Hasil pengujan sistem

\begin{tabular}{lcccc}
\hline \multicolumn{1}{c}{ Metode Query Expansion (QE) } & $\begin{array}{c}\text { Treshold } \\
\text { cosine }\end{array}$ & $\begin{array}{c}\text { Recall } \\
\mathbf{( \% )}\end{array}$ & $\begin{array}{c}\text { Precision } \\
\mathbf{( \% )}\end{array}$ & $\begin{array}{c}\text { F-measure } \\
\mathbf{( \% )}\end{array}$ \\
\hline WE + Pseudo Relevance Feedback & 0.21 & 100 & 70 & 82 \\
Word Embedding (Rattinger, Goff, \& Guetl, 2018) & 0,11 & 100 & 20 & 33 \\
$\begin{array}{l}\text { Pseudo Relevance Feedback (Vaidyanathan, Das, \& } \\
\text { Srivastava, 2015) }\end{array}$ & 0.14 & 83 & 71 & 77 \\
Tanpa QE (Singh, Paste, Shinde, Patel, \& Mishra, 2018) & 0.15 & 100 & 44 & 62 \\
\hline
\end{tabular}

Berdasarkan hasil pengujian didapatkan bahwa penggunaan word embedding dan $p$ seudo relevance feedback sukses dalam melakukan QE terbukti dengan nilai F1 mencapai 82,35\%. Jika dihitung akurasinya mencapai 70\%, hasil tersebut lebih baik daripada chatbot tanpa menggunakan QE yang dilakukan Singh, dkk. (2018) yang hanya mencapai akurasi $68,51 \%$. Terdapat beberapa kekurangan dalam sistem, yaitu query yang dimasukkan oleh pengguna yang diproses ke dalam word embedding tidak dapat mencari kemiripan kata berdasarkan makna katanya. Word embedding yang digunakan hanya mencari kemiripan kata berdasarkan kata yang muncul bersama dalam satu dokumen atau cooccurrence. Sebagai contoh, jika diinputkan query "makan" ke dalam sistem, word embedding akan mencari kata yang sering muncul bersama dengan kata "makan" di dalam corpus. Maka, yang muncul adalah kata: "minum", "sarapan", "memasak", "menyantap", "tidur" yang menyebabkan berkurangnya makna kata "makan".

\section{Kesimpulan}

Berdasarkan hasil penelitian penggabungan word embedding dan $p$ seudo relevance feedback sebagai metode QE pada aplikasi chatbot untuk konsumsi makanan dan minuman ibu hamil, disimpukan bahwa word embedding mencari kemiripan antarkata yang memiliki jumlah kemunculan bersama dalam satu dokumen. Namun, word embedding tidak dapat mencari kemiripan kata berdasarkan makna kata atau 
keterkaitan dengan perbedaan makna kata. Hal ini tentunya berseberangan dengan tujuan QE yang memperkaya query dengan kata-kata yang mirip bedasarkan makna kata. Dengan menggunakan pseudo relevance feedback, QE hasil word embedding dipilih kata yang terdapat dalam dokumen jawaban. Hasil uji coba menunjukan bahwa QE menggunakan word embedding dan pseudo relevance feedback pada chatbot dapat mengatasi query masukan dari pengguna yang ambigu dan alami sehingga dapat memberikan jawaban yang relevan kepada pengguna.

\section{Referensi}

Agung, G. (2011, April 20). 17 Pertanyaan Yang Sering Ditanyakan Ibu Hamil. Retrieved from Dr. Gregorius Agung, SpOG: http://greg-spog.com/kebidanan-kandungan/17-pertanyaan-yangsering-ditanyakan-ibu-hamil/

Buckley, C., Salton, G., \& Allan, J. (1994). The Effect of Adding Relevance Information in a Relevance Feedback Environment. SIGIR '94 (pp. 292-300). London: Springer.

Dalpiaz, F., Ferrari, A., Franch, X., \& Palomares, C. (2018). Natural Language Processing for Requirements Engineering: The Best Is Yet to Come. IEEE Software, 35(5), 115-119.

Dierk, S. F. (1972). The SMART retrieval system: Experiments in automatic document processing. IEEE Transactions on Professional Communication, PC-15(1), 17.

Domarco, D., \& Iswari, N. M. (2017). Rancang Bangun Aplikasi Chatbot Sebagai Media Pencarian Informasi Anime Menggunakan Regular Expression Pattern Matching. ULTIMATICS: Jurnal Ilmu Teknik Informatika, 9(1), 19-24.

Fitriana, D. A. (2016, September 1). Gizi Seimbang Ibu Hamil. Retrieved from Jurusan Gizi Fakultas Kedokteran Universitas Brawijaya: http://gizi.fk.ub.ac.id/gizi-seimbang-ibu-hamil/

Indarini, N. (2018, Juli 17). Kumpulan Pertanyaan Seputar 'Bolehkah Ibu Hamil Makan...'. Retrieved from HaiBunda.com: https://www.haibunda.com/kehamilan/20180716143654-49-23095/kumpulanpertanyaan-seputar-bolehkah-ibu-hamil-makan

Kuzi, S., Shtok, A., \& Kurland, O. (2016). Query Expansion Using Word Embeddings. CIKM '16 Proceedings of the 25th ACM International on Conference on Information and Knowledge Management (pp. 1929-1932). Indianapolis, Indiana, USA: ACM.

Lee, H.-Y., \& Lee, L.-S. (2014). Improved Semantic Retrieval of Spoken Content by Document/Query Expansion with Random Walk Over Acoustic Similarity Graphs. IEEE/ACM Transactions on Audio, Speech, and Language Processing, 22(1), 80-94.

Liu, Q., Huang, H., Lut, J., Gao, Y., \& Zhang, G. (2017). Enhanced word embedding similarity measures using fuzzy rules for query expansion. 2017 IEEE International Conference on Fuzzy Systems (FUZZIEEE). Naples, Italy: EEE.

Ludviani, R., Hayati, K. F., Arifin, A. Z., \& Purwitasari, D. (2015). Optimasi Pembobotan pada Query Expansion dengan Term Relatedness to Query-Entropy based (TRQE). Jurnal Buana Informatika, 6(3), 203-212.

Mothe, J., Savoy, J., Kamps, J., Pinel-Sauvagnat, K., Jones, G., Juan, E. S., . . . Ferro, N. (2015). Experimental IR Meets Multilinguality, Multimodality, and Interaction. 6th International Conference of the CLEF Association (CLEF'15). Toulouse, France: Springer.

Nie, L., Jiang, H., Ren, Z., Sun, Z., \& Li, X. (2016). Query Expansion Based on Crowd Knowledge for Code Search. IEEE Transactions on Services Computing, 9(5), 771-783.

Ooi, J., Ma, X., Qin, H., \& Liew, S. C. (2015). A survey of query expansion, query suggestion and query refinement techniques. 2015 4th International Conference on Software Engineering and Computer Systems (ICSECS). Kuantan, Malaysia: IEEE.

Putra, F. N., Effendi, A., \& Arifin, A. Z. (2018). Pembobotan Kata berdasarkan Kluster untuk Peringkasan Otomatis Multi Dokumen. Jurnal Linguistik Komputasional, 1(1), 17-22.

Rattinger, A., Goff, J.-M. L., \& Guetl, C. (2018). Local Word Embeddings for Query Expansion based on Co-Authorship and Citations. BIR 2018 Workshop on Bibliometric-enhanced Information Retrieval (pp. 46-53). Grenoble, France: CEUR-WS.

Reshma, E. U., \& Remya, P. C. (2017). A review of different approaches in natural language interfaces to databases. 2017 International Conference on Intelligent Sustainable Systems (ICISS). Palladam, India: IEEE.

Query Expansion menggunakan Word Embedding dan Pseudo Relevance Feedback http://doi.org/10.26594/register.v5i1.1385

(C) 2019 Register: Jurnal IImiah Teknologi Sistem Informasi. Semua hak cipta dilindungi undang-undang. 
Şenel, L. K., Utlu, İ., Yücesoy, V., Koç, A., \& Çukur, T. (2018). Semantic Structure and Interpretability of Word Embeddings. IEEE/ACM Transactions on Audio, Speech, and Language Processing, 26(10), 1769 -1779 .

Singh, R., Paste, M., Shinde, N., Patel, H., \& Mishra, N. (2018). Chatbot using TensorFlow for small Businesses. 2018 Second International Conference on Inventive Communication and Computational Technologies (ICICCT). Coimbatore, India: IEEE.

Vaidyanathan, R., Das, S., \& Srivastava, N. (2015, February 18). Query Expansion Strategy based on Pseudo Relevance Feedback and Term Weight Scheme for Monolingual Retrieval. Retrieved from arXiv: https://arxiv.org/abs/1502.05168

Wang, X., Fang, H., \& Zhai, C. (2008). A Study of Methods for Negative Relevance Feedback. SIGIR '08 Proceedings of the 31st annual international ACM SIGIR conference on Research and development in information retrieval (pp. 219-226). Singapore: ACM.

Xu, B., Lin, H., Lin, Y., Yang, L., \& Xu, K. (2018). Improving Pseudo-Relevance Feedback With Neural Network-Based Word Representations. IEEE Access, 6, 62152-62165.

Yan, R., \& Gao, G. (2017). Pseudo-Based Relevance Analysis for Information Retrieval. 2017 IEEE 29th International Conference on Tools with Artificial Intelligence (ICTAI). Boston, MA, USA: IEEE.

Young, T., Hazarika, D., Poria, S., \& Cambria, E. (2018). Recent Trends in Deep Learning Based Natural Language Processing [Review Article]. IEEE Computational Intelligence Magazine, 13(3), 55 -75. 